\title{
ZAPIS Z TERENU CODZIENNOŚCI. PRZYCZYNEK DO ROZMYŚLAŃ O IZOLACJI (W DOBIE PANDEMII)
}

AgNiESZKa KarPIEL

Instytut Nauk o Kulturze UŚ

Institute of Cultural Studies, University of Silesia in Katowice agnieszka.karpiel@us.edu.pl

ORCID: 0000-0003-1777-2915

JesSICA KuFA

Instytut Nauk o Kulturze UŚ

Institute of Cultural Studies, University of Silesia in Katowice jessica.kufa@us.edu.pl

ORCID: 0000-0002-0858-0228

Codzienność jest nudna $a^{1}$ to akcja fotograficzna nagrodzona w konkursie „Do sztuki gotowi Start!”. Do udziału w niej losowo wybrałyśmy siedem osób ${ }^{2}$, a każda $\mathrm{z}$ nich przez 24 godziny fotografowała swoją codzienność za pomocą aparatu do fotografii natychmiastowej Fuji Instax mini $8^{3}$, posiadając tylko

1 Autorkami i realizatorkami pomysłu były: Agnieszka Karpiel, Jessica Kufa i Gabriela Styrkowicz. W efekcie ich pracy 20 grudnia 2019 r. w katowickim oddziale BWA odbył się wernisaż wystawy, na której zaprezentowane zostały 127 fotografie wykonane w ciągu siedmiu dni.

2 Liczba chętnych do wzięcia udziału w projekcie przerosła nasze oczekiwania. W ciągu trzech dni do akcji zgłosiło się 91 osób, stąd decyzja o losowaniu. Zależało nam na zachowaniu jak najmniejszej ingerencji w dobór uczestników. Jedyną informację, która miałyśmy w momencie losowania, było imię, nazwisko i wiek (konieczna była pełnoletniość).

3 Uczestnicy projektu mieli do dyspozycji aparaty: Instax Mini 8 i Instax Wide. Sięgnęłyśmy po technikę fotografii natychmiastowej z dwóch powodów. Po pierwsze, w swoich założeniach przybliża nas do popularnej obecnie estetyki instagramowej, która wydaje się bezspornie królować na polu prezentowania codzienności. Po drugie - idea, którą prezentuje fotografia natychmiastowa, zawarta w haśle reklamowym firmy Polaroid: „Nie będziesz mógł przestać. Nagle wszędzie widzisz obrazy... A teraz naciśnij czerwony guzik... Rrrr... Cyk! I gotowe!” 
(albo aż!) 20 wkładów. Prowokujący w naszym odczuciu tytuł zdradzać miał istotę tego działania, jednak każdy z uczestników musiał na swój sposób zmierzyć się z fotograficznym przedstawieniem swojej codzienności. Mimo dostrzegalnych punktów wspólnych każda doba otwierała przed nami nowe interpretacyjne przestrzenie. Najbardziej charakterystyczne było zmaganie się uczestników z aparatem fotograficznym, który przestał być tylko narzędziem służącym do zapisu, ale stał się kolejnym (ósmym) i autonomicznym uczestnikiem projektu. Aparat, będąc świadkiem codziennego życia, pozwalał na intencjonalne wyrywanie chwil i obrazów, podkreślał relacje w przestrzeni miasta i w intymnej przestrzeni domów, tworzył nowe znaczenia tego, co zostało zobaczone i doświadczone, a także stał się narzędziem władzy w rękach fotografujących. Jednak na przekór postulatom, które sugerują uważne fotograficzne bycie „tu i teraz”, i próbując przeciwstawić się myśli propagatora „decydującego momentu”, Henriego Cartiera-Bressona, powstała opowieść o nudnej codzienności, ukryta za widokiem budynków i zwyczajnych przedmiotów, za relacjami z ludźmi, których spotykamy, za miejscami, w których bywamy, i za okrytymi banalnością czynnościami. Interpretując fotografie wykonane przez uczestników i uczestniczki, traktowałyśmy je zbiorczo (nie skupiałyśmy się na przypisaniu ich do poszczególnych dni ani na autorstwie), zależało nam bowiem na zajrzeniu za kulisy procesu fotograficznego i zadaniu pytania o postrzeganie codzienności (rutyny, powtarzalności, nudy) poprzez fotograficzne zapośredniczenie.

(B. von Brauchitsch, Mała historia fotografii, tłum. J. Kożbiał, B. Tarnas, Warszawa 2004, s. 218), zdaje się dyskutować $\mathrm{z}$ hasłem wywoławczym naszego działania, czyli codzienną nudą. Po trzecie, aparat instax ogranicza do minimum konieczność posiadania odpowiedniego technicznego przygotowania do fotografowania.

${ }^{4} \mathrm{Na}$ spotkaniu z uczestnikami i uczestniczkami projektu poprzedzającym działanie fotograficzne inicjatorki akcji nawiązały do metody fotograficznej nazwanej „decisive moment” zaproponowanej przez Cartiera-Bressona, która zakłada, że osoba fotografująca powinna czekać na jeden właściwy moment naciśnięcia spustu migawki. Autorki akcji zachęcały do krytycznego spojrzenia na to popularne wyczekiwanie i popularne postrzeganie fotografii jako działania, które pozwala zatrzymać moment. Istotniejsze bowiem wydaje się samo bycie osoby fotografującej w procesie obserwowania i zapisywania codzienności, zapośredniczone przez aparat fotograficzny, niż wyrywanie poszczególnych chwil z życia. 
Codzienność istnieje jednocześnie najbliżej i najdalej od naszej świadomości, jest trudna do uchwycenia, a zarazem niemożliwa do pominięcia, ponieważ codzienność to „teraz” z perspektywy najbliższej „przyszłości”. Do codzienności nie ma powrotu. Natychmiast „rozpływa się” i „krzepnie” w micie, w tym, co „niewyrażalne”" . Łatwiej w pamięć zapadają ważne momenty i wyjątkowe chwile. Codzienność jest niewidzialna, a jej sens często wydaje się nieuchwytny. Jej ślady odnajdujemy w efektach powtarzalnych działań, ale niemożliwe jest wyabstrahowanie jej poza rytm upływających godzin, dni tygodnia, miesięcy, lat. To czyni codzienność tak podobną do fotografii, ponieważ - jak twierdzi John Berger - „formalny porządek fotografii nie objaśnia niczego" ". Oglądanie zdjęć w określonej kolejności pozwala uwierzyć na chwilę w możliwość ulotnego poznania kontekstu, w jakim są zawieszone, jednak tak jak w przypadku codzienności, przeglądanie kalendarza i czytanie zapisów w dzienniku tylko złudnie pozwala zatrzymać porządek wydarzeń. Nadal jest to tylko przyglądanie się powierzchni, bo „[...] prawdziwa treść fotografii jest niewidzialna, wynika ona z gry z czasem, a nie $\mathrm{z}$ formą. Fotografie niosą ze sobą świadectwo podjętych przez ludzi wyborów. Nie chodzi o wybory dotyczące sfotografowania tego czy innego obiektu, lecz sfotografowania go w tym lub innym momencie"7.

Próba przedstawienia na zdjęciach codzienności jest podwójnie niemożliwa. Okruch dnia jest tylko jednym z elementów większej, nieokreślonej całości, zanurzonej w powtarzalności działań, a „obraz interpretuje świat, tłumacząc go na swój własny język. Fotografia nie dysponuje własnym językiem”. Według Bergera „odczytywać fotografie uczymy się tak, jak

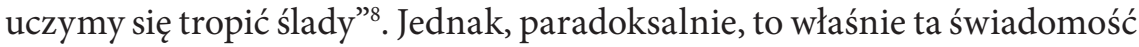
niespełnienia wstępnych założeń projektu pozwoliła przyjrzeć się codzienności i śladom ukrytym między kadrami.

Od akcji minęło sześć miesięcy, ten czas wydaje się bardzo odległy, a jednocześnie pandemia Covid-19 rzuciła wszystkim podobne wyzwanie. Oto,

5 R. Sulima, Antropologia codzienności, Kraków 2000, s. 7.

6 J. Berger, Zrozumieć fotografię, tłum. K. Olechnicki, [w:] Badania wizualne w działaniu. Antologia tekstów, red. M. Frąckowiak, M. Krajewski, K. Olechnicki, Kraków 2011, s. 205.

7 Ibidem.

8 Ibidem, s. 206. 
zmuszeni do pozostania w domach, możemy wnikliwie przyglądać się naszej (pandemicznej) codzienności. Każdy może stać się badaczem swojego mikroświata, a odejście od nadmiaru działań podejmowanych przed czasem społecznej kwarantanny daje możliwość spojrzenia na rutynowe czynności z innej perspektywy. To doświadczenie skłoniło nas do ponownego przyjrzenia się fotografiom powstałym podczas projektu. Wybrałyśmy dziewięć kadrów, które połączyłyśmy w trzy tryptyki. Autorami zdjęć są: Kacper Krzętowski, Barbara Błaż i Roksana Romańska (il. 1-3). Każda z wykonanych przez nich fotografii jest interpretacyjnym laboratorium codzienności zarówno czasu przed, jak i w trakcie izolacji.

Przy opracowywaniu założeń akcji Codzienność jest nudna inspirowałyśmy się badaniami etnograficznymi, które są nam bliskie ze względu na nasze zainteresowania naukowe, ale próbujemy korzystać $\mathrm{z}$ ich potencjału także przy działaniach artystycznych i animacyjnych. Ewa Klekot, interpretując wystawę Zofii Rydet, doszukuje się podobnej inspiracji:

Pod wieloma względami strategia Rydet przypomina pracę etnografa w tym drugim znaczeniu tego słowa - gdy etnografia oznacza metodę badawczą polegającą na „byciu tam”, by móc po powrocie przedstawić relację z tego „bycia” publiczności „u siebie”, „w domu”. Podczas pobytu w terenie - „tam” - etnograf zbiera materiały, które mogą mieć różną postać: tekstu pisanego, zapisu głosowego, rysunków, zdjęć czy filmów, i których z zasady często się nie docenia?

To jednak, co u Rydet jest zapisem z prowadzenia badań, formą dziennika badawczego, w naszym działaniu jest wiedzą wywołaną, która zostaje wypowiedziana podobnie jak słowa w czasie prowadzenia wywiadu przez informatorów i porządkowana oraz analizowana przez kuratorki. Podobnie jak w wywiadzie antropologicznym ściśle określony kwestionariusz kieruje rozmowę na interesujący badaczkę temat, tak my określiłyśmy założenia działania i istotne dla nas problemy, wokół których mieli poruszać się fotografujący. I tak jak podczas wywiadów to, jaką wiedzę pozyskałyśmy, wychodziło daleko poza nasze przewidywania.

9 J. Dziewit, A. Pisarek, Ocalać. Zofia Rydet a fotografia wernakularna, Łódź 2020, s. 59. 

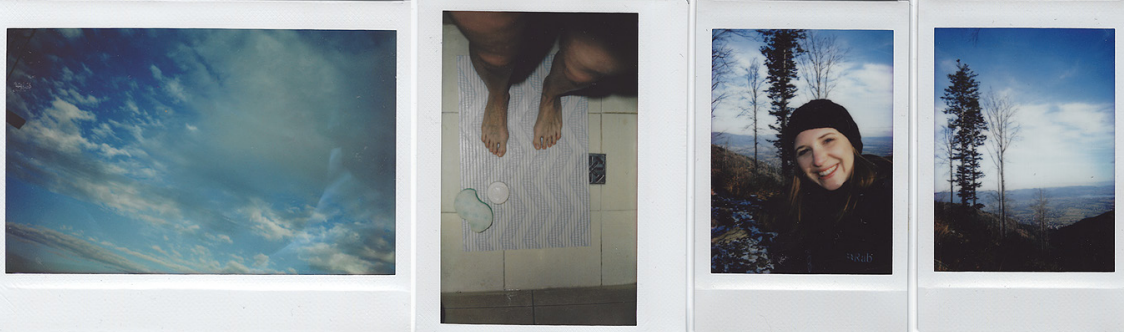

Il. 1-3. Codzienność jest nudna, tryptyk nr 1: fotografie K. Krzętowskiego, B. Błaż i R. Romańskiej

Nasze działanie fotograficzne wpisuje się także w szerszą panoramę zjawisk artystycznych. Aparatu do fotografii natychmiastowej w celu opisu i prezentacji własnej codzienności użył w 2008 roku Wojciech Puś, realizując film Instant, któremu towarzyszyły zdjęcia wykonane polaroidem. Jak sam mówi o swojej pracy, nagrania i fotografie przybierają formę „dziennika, w którym znalazły się sytuacje intymne, portrety wideo, dokumentacje codzienności, rejestracje zjawisk naturalnych, a także estetyczna fascynacja samym medium wideo, jego potencjałem wizualnym, materią obrazu cyfrowego" 10 . Innymi projektami fotograficznymi wykorzystującymi tę technikę, traktującymi o codzienności i pozostającymi w estetyce spontaniczności oraz niedopracowania są zdjęcia Andrei Ruedy, robione znajomym i przedmiotom, które towarzyszą jej każdego dnia. Uczestnicy projektu wielokrotnie fotografowali elementy przestrzeni miejskiej. To odsyła nas do prac Dennisa Hoppera, który stworzył cykl polaroidów Colors.

Działanie każdego z fotografujących uczestników przypomina selfie złożone z dwudziestu zdjęć. Analiza pojedynczego zdjęcia rzadko by na to wskazywała. Selfie jest obrazem samego siebie w dość wąskim tego słowa znaczeniu - jest to obraz własnego ciała, najczęściej twarzy, wykonany z niewielkiej odległości, który nie ukrywa sposobu wykonania zdjęcia (medium) ${ }^{11}$. $\mathrm{Na}$ tryptyk nr 1 składają się zdjęcia, z których jedno, przedstawiające nogi biorącej prysznic fotografującej, jest selfie w ścisłym tego słowa znaczeniu.

10 W. Puś, https://artmuseum.pl/pl/filmoteka/praca/pus-wojciech-instant [dostęp 14.09.2020].

${ }^{11}$ N. Mirzoeff, Jak zobaczyć świat, tłum. Ł. Zaremba, Kraków - Warszawa 2016, s. 79. 
Kolejne zdjęcie to właściwie dwa obrazy, bardzo tę konwencję przypominające, choć ten, kto używał aparatu do fotografii natychmiastowej typu Fuji Instax mini 8, zapewne domyśla się, że bardzo trudno zrobić nim sobie tak dobrze wykadrowane zdjęcie ${ }^{12}$. Na fotografii Roksany Romańskiej widzimy uczestniczkę projektu, która bezspornie zaaranżowała to zdjęcie. Ten, kto naciskał spust migawki, był jedynie wykonawcą jej zamysłu kompozycyjnego, a ponadto na estetykę zdjęcia istotny wpływ miały ustawienia samego aparatu, które autorka wzięła wcześniej pod uwagę. Pierwsze zdjęcie przedstawia niebo, które fotografujący widział, idąc do dentysty.

Zdjęcia przedstawiające codzienność można określić mianem dokumentu - miały przedstawiać przecież coś, co istnieje, i jak w przypadku wielu innych dokumentów fotografujący włożyli wiele wysiłku w to, aby zdjęcia oddawały rzeczywistość taką, jaka jest. To jednak cel właściwie niemożliwy do spełnienia ${ }^{13}$. Szczególnie gdy rzeczywistość, którą chcemy dokumentować, jest czymś tak ulotnym i zarazem bliskim, jak własna codzienność. Każdy z autorów dokonał wyboru sposobu, w jaki sposób sprostać temu wyzwaniu. Nadana odgórnie liczba zdjęć oraz brak możliwości ich usuwania bądź obróbki uniemożliwiały realizację pewnych pomysłów, każąc fotografującym pogodzić się z ich ograniczonym wpływem na efekt końcowy. Pozostawał wybór kadru, w przypadku instaxa utrudniony o tyle, że obraz na zdjęciu jest przesunięty względem tego widocznego w wizjerze. W przypadku cyfrowych selfie autor ma znaczny wpływ na komunikat, który konstruuje, kreując siebie poprzez zdjęcia, ich wybór i obróbkę cyfrową, np. nakładanie filtrów ${ }^{14}$. Uczestnicy działania nie mieli tej możliwości. Ich fotografie są eksperymentem, mającym dać wiedzę umożliwiającą zadanie pytań o codzienność, o kreowanie codzienności, o osobisty performans.

12 Fuji Instax mini 8 nie posiada, tak jak np. model mini 9, lusterka do robienia selfie. Wielu uczestników projektu po raz pierwszy korzystało z tego urządzenia. A przy wynikającej z założeń akcji ograniczonej liczby zdjęć nie mieli sposobności wprawić się w robieniu tego typu zdjęć. Teza o wyjątkowej trudności w zrobieniu sobie samemu zdjęcia jest wynikiem obserwacji konkretnych fotografujących używających konkretnego modelu aparatu. W przypadku innych modeli aparatu lub osób sprawnie ich używających teza ta mogłaby okazać się bezzasadna.

13 A.M. Potocka, Fotografia, Warszawa 2010, s. 158.

${ }_{14}$ N. Mirzoeff, op. cit., s. 78. 
Jednak zdjęcie ukazujące niebo zauważone w drodze do dentysty rezygnuje z przedstawienia rzeczywistości na rzecz wprowadzenia niepokoju symbolicznego. Na zdjęciu widzimy błękit i białe chmury, lecz nie to jest jego treścią. Idąc tropem myśli Rolanda Barthes'a przedstawionej w Świetle obrazu $u^{15}$, niebo byłoby studium - rozpoznawalnym dla wszystkich z danego kręgu kulturowego obrazem niosącym zrozumiałe treści. Punktum jest elementem spoza kultury, bliskim osobistym przeżyciom i narastającym w znaczenia $\mathrm{z}$ czasem. Jest tym, co według Barthes'a sprawia, że fotografia zostaje w naszej pamięci oraz że możemy powiedzieć o niej coś więcej niż tylko to, że nam się podoba. Nie należy brać pod uwagę, czy założenia fotografującego zostały spełnione ani artystycznych walorów obrazu ${ }^{16}$. Zdjęcie nieba może nas znudzić, widzieliśmy ich zapewne wiele, ale osobiście nie potrafimy się oprzeć refleksji nad takim obrazem wizyty u dentysty. To zatrzymanie wzroku na niebie i zaproszony do widzenia aparat fotograficzny pokazuje nam czas inny niż czas wykonywanych czynności. Wizyta u dentysty trwa około 30 minut; zrobienie zdjęcia - zwłaszcza w fotografii natychmiastowej - może zająć tylko kilka sekund, jednak to niebo trwa w nas w czasie wykraczającym poza czas ludzki. To samo niebo widoczne jest z okna, ulicy i sklepu. Niebo łączy nas wszystkich. Tych zmuszonych do spędzania czasu w domu, tych, którzy narażając swoje zdrowie, muszą pracować, nas - ludzi i wszystkie istnienia pozaludzkie. To właśnie ten pozaludzki czas może być łatwiejszy do dostrzeżenia w czasie pandemii.

15 R. Barthes, Światło obrazu, tłum. J. Trznadel, Warszawa 2008.

16 Dla założeń projektów ważne było, aby nie estetyzować robionych fotografii. Dlatego nie odrzucaliśmy zdjęć, które były prześwietlone lub odwrotnie - niedoświetlone, a nawet takich, o których autorzy mówili, że „nie wyszły”. W sensie metaforycznym miało to dla nas znaczenie, gdyż traktowałyśmy te „gorsze” zdjęcia jako momenty codzienności, które są nieinteresujące lub, według nas samych, niewarte opowiedzenia innym. Jest jednak jasne, że istnieje „poetyka polaroida”. Jest to estetyka, w której poruszają się artyści tacy jak Andy Warhol i David Hockney, ale także młodsi fotografowie, np. Wojciech Puś, który zrealizował film Instant w 2008 r. w estetyce polaroidu, któremu towarzyszyły fotografie natychmiastowe. „Estetyka polaroidu” polega na obecności błędów, na niedoświetleniu. Zdjęcia powstałe w tej poetyce można uznać za spontaniczne i nostalgiczne. 
Zdjęciowe autoportrety wykonywano właściwie, od kiedy zaczęto fotografować, jednak samo selfie ściśle wiąże się z rozwojem mediów społecznościowych oraz rozpowszechnieniem telefonów komórkowych $\mathrm{z}$ aparatami fotograficznymi. W pierwszej dekadzie XXI wieku na portalach społecznościowych często umieszczano selfie wykonane w lustrze, w którym odbijało się światło lampy błyskowej, niejednokrotnie przysłaniające osobę znajdującą się na zdjęciu. Jednak wkrótce aparaty fotograficzne pojawiły się z przodu smartfonów, przy tym znacząco rozszerzono ich ustawienia, ułatwiając osiągnięcie pożądanego efektu ${ }^{17}$. Uczestnicy projektu korzystali z modelu aparatu Fuji Instax mini 8, który nie posiada technicznego rozwiązania umożliwiającego podgląd zdjęcia wykonywanego samemu sobie ani też dodatkowego lusterka zakładanego na obiektyw. Dlatego fotografujący, robiąc zdjęcie swojemu ciału, nie wychodzili poza perspektywę własnego widzenia owego ciała. Jeżeli więc nie perspektywę widzenia, to co daje aparat fotograficzny, aby spojrzenie na siebie i swoją codzienność było czymś innym niż praca bez medium? Instax poprzez swoje ustawienia odpowiada za bardzo charakterystyczny wygląd zdjęcia. Przypomina to pracę etnograficzną nad materiałem badawczym: sam proces robienia zdjęć i ustawienia aparatu przypomina proces analizy, a tworzenie interpretacji jest niczym wejście do antropologicznej ciemni ${ }^{18}$. Selfie czy fotografowanie swojej codzienności jest aktem kreacyjnym nastawionym także na komunikację (projekt zakładał pokazanie zdjęć w galerii sztuki), a także soczewką, w której przyglądamy się sobie. Poprzez selfie przedstawiamy nasze relacje ze światem - z miejscem, przedmiotami i ludźmi ${ }^{19}$. Ta obserwacja siebie powraca w innym kontekście, we wspomnianym obrazie R. Romańskiej składającym się z dwóch zdjęć, które przedstawiają ten sam górski krajobraz, z tą różnicą, że na jednym z nich znajduje się uczestniczka projektu. Te zdjęcia to przyglądanie się

17 N. Mirzoeff, op. cit., s. 77.

18 J. Dziewit, A. Pisarek, Ciemnia antropologiczna, [w:] Patrzenie i widzenie w kontekstach kulturoznawczych, red. J. Dziewit, M. Kołodziej, A. Pisarek, Katowice 2016, s. 11.

19 J. Dziewit, Od budowania tożsamości do zniewolenia. Rozważania o funkcji fotografii w kulturze Zachodu, [w:] Pomiędzy tożsamościa a obrazem, red. M. Markiewicz, A. Stronciwilk, P. Ziegler, Katowice 2016, s. 188. 
światu „beze mnie” i „ze mną” lub światu, w którym „jestem, choć nie zawsze widoczna”.

Wydawać by się mogło, że codzienność jest wyznaczana tylko przez czas i powtarzalność, które współcześnie zamykamy w określeniu „24/7”20. Jednak, jak przekonywałyśmy wcześniej, to także świadomość czasu, który istnieje poza nami. Codzienność to przestrzenie, w których jej i jej trwania doświadczamy. Pokój, mieszkanie, blok, miasto - miejsca, które są nam znane, w których przebywamy niemal codziennie, stają się areną naszych powszednich działań. Codzienne mikro-historie dziejące się za betonowymi i kolorowymi fasadami, za drzwiami, które widzimy na zdjęciach składających się na tryptyk nr 2 (il. 4-6). Przestrzeń i czas zdają się walczyć o naszą uwagę, nieustannie konkurując ze sobą, a w codzienności, jak w soczewce, skupiają się konsekwencje tej walki. Z jednej strony „24/7” to czas bezczasowy, pozbawiony wszelkich materialnych form oraz rozpoznawalnych cezur, nieuznający następstwa lub powtarzalności wydarzeń ${ }^{21}, \mathrm{z}$ drugiej to właśnie podporządkowanie się władzy czasu odmierzanego przez zegar wyznacza nam wejścia i wyjścia, zamykanie i otwieranie, przybywanie na czas, spóźnianie się, czekanie, przemierzanie korytarzy, przebywanie w pomieszczeniach itd. Otwarcie przed kimś drzwi to także gest zaproszenia do „mojego” świata, często najpilniej strzeżonego przed wzrokiem innych; zamknięcie ich za kimś to wpisanie go/jej na moment do bezpiecznego,
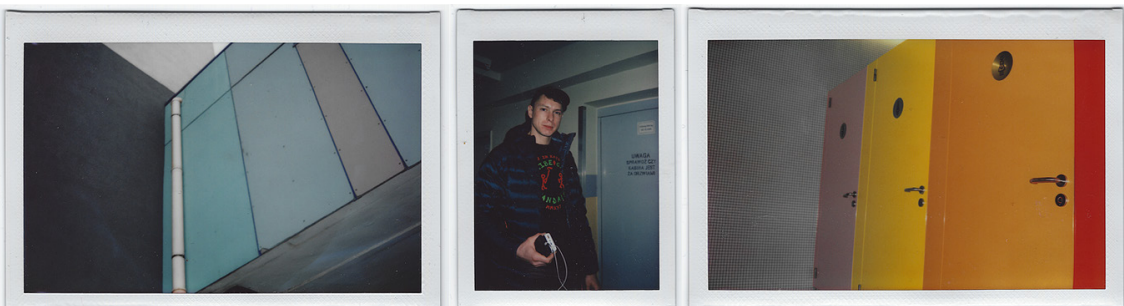

Il. 4-6. Codzienność jest nudna, tryptyk nr 2: fotografie K. Krzętowskiego, R. Romańskiej i B. Błaz

20 J. Crary, Późny kapitalizm i koniec snu, tłum. D. Żukowski, Kraków 2015.

${ }^{21}$ Ibidem, s. 50. 
intymnego wnętrza codzienności. Ściany i drzwi przywołują skojarzenie z murem i zaporą, miejscem, które odczytujemy jako znak STOP, co w kontekście sporu o codzienność, toczącego się pomiędzy aparatem fotograficznym a osobą fotografującą, zdaje się możliwością przechwycenia czasu i zmuszenia oglądającego do chwili zatrzymania, niespełnienia jednej z głównych obietnic fotografii - pokazania wszystkiego.

W fotografiach, które mają przedstawiać codzienność, szukamy śladów obecności, odbić w lustrach, cieni dostrzeżonych na murach, które pozwolą potwierdzić bycie „tu i teraz” (tryptyk nr 3; il. 7-9). Tak jak spotkanie z innym człowiekiem zapewnia nas o naszym byciu, ponieważ „[...] inni nas nie stwarzają, a jedynie zapewniają nas o naszej obecności. Nie możemy bowiem sami dla siebie potwierdzić własnego ja”22, tak własny cień, który udaje się zatrzymać na fotografii, pozwala zauważyć siebie. Poczucie tożsamości i ciągłości bycia dostrzec można w zdjęciach naszych bliskich i fotografiach, które przywołują wspomnienie o nas z przeszłości. W portrecie matki możemy odnaleźć cząstkę nas samych, a fotografie z dzieciństwa wypełniają sieć wspomnień o codzienności „z kiedyś”. Zdjęcia ustawione na półce, fotografie w towarzystwie obrazów będących portretami świętych to przedstawienie nierozerwalnego związku, jaki można dostrzec pomiędzy codziennością a świętością obrazu. To także dowód na ciągłe napięcie istniejące pomiędzy odnalezionym wizerunkiem nas i naszych bliskich a symulakrum przedstawiającym wyobrażenie świętych. Wszystkie te obrazy wyłaniają się z enigmatycznej ciemności, gdy na ułamek sekundy uda się zajrzeć głębiej niż w pierwszy plan, najczęściej najlepiej oświetlony i dostrzegalny. Fotografując codzienność, szukamy obrazu „ja”, tak aby chociaż na chwilę zyskać pewność, „że mój obraz, ruchomy, przerzucany miedzy tysiącem zmieniających się zdjęć, zależnie od okoliczności i wieku, zgadzał się zawsze $\mathrm{z}$ moim ja"23, na ułamek sekundy wychylić się za barierkę na balkonie i szukać odpowiedzi z zamkniętymi oczami.

Akcja Codzienność jest nudna odbyła się na kilka miesięcy przed ogłoszeniem pandemii. Ten trudny czas zbiega się z momentem podsumowania działań i opracowywania albumu prezentującego powstałe w ich wyniku

${ }^{22}$ M. Markiewicz, Tożsamość zobrazowana, czyli o wartości zamykania oczu, [w:] Pomiędzy tożsamością a obrazem, op. cit., s. 188.

${ }^{23}$ R. Barthes, op. cit., s. 25. 

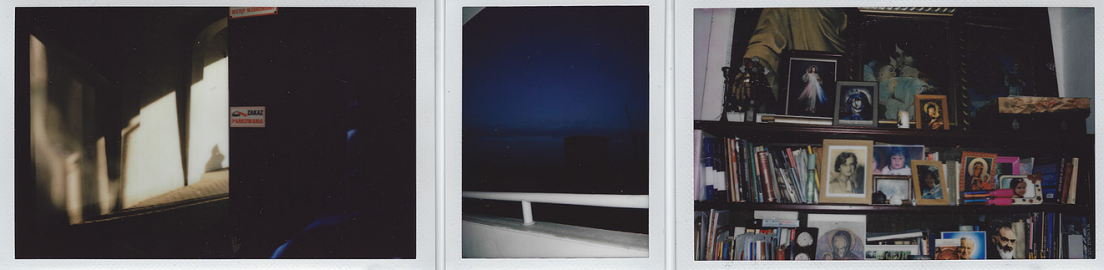

Il. 7-9. Codzienność jest nudna, tryptyk nr 3: fotografie K. Krzętowskiego, R. Romańskiej i B. Bła $\dot{z}$

zdjęcia. Zadaniem, jakie postawiłyśmy przed uczestnikami, było spojrzenie poprzez aparat na swoją codzienność. Interesowało nas to, co skrywa się pod tym pojęciem. Nie prezentowałyśmy konkretnej definicji codzienności, użyłyśmy jedynie prowokującego (dla niektórych) uczestników hasła „codzienność jest nudna”. Wyrażenie okazało się na tyle niejednoznaczne, że pozwoliło na swobodę w jego odczytaniu. Dla jednych hasło było inspiracją do tego, by powiedzieć, że ich codzienność jest obfita w różne działania i myśli, dzięki którym nie ma mowy o nudzie. Inni zaś niemal z wdzięcznością przyjęli hasło jako prawdę, aby pokazać powszednie rzeczy, z którymi mamy do czynienia na co dzień i do których jesteśmy przyzwyczajeni na tyle, że potrzebujemy innej perspektywy, by je dostrzec.

Niezależnie od nastawienia uczestników teza zawierająca się w tytule działania została obalona w momencie jej wypowiadania. Samo skierowanie na coś lub kogoś obiektywu świadczy już bowiem o zainteresowaniu fotografującego. Powód tego zainteresowania nie zawsze przychodzi wraz z naciśnięciem spustu migawki, często ujawnia się dopiero na etapie porządkowania wykonanych zdjęć, ich przeglądania i wybierania tych, które, no właśnie - są warte uwagi. Uczestnicy akcji nie mieli możliwości odrzucania zdjęć, a dla nas na etapie konkretyzowania się interpretacji wszystkie zdjęcia były istotne. I choć zarówno uczestnicy, jak i my jako organizatorki mieliśmy ulubione fotografie oraz takie, o których łatwo byłoby nam zapomnieć, to stworzyłyśmy z nich wszystkich wspólną i wielowątkową narrację. Być może w tej strategii udało nam się zachować coś z tytułowej nudy - zgody na to, aby zaprezentowane zostały wszystkie fotografie. 
Prace nad podsumowaniem projektu skłoniły nas do rozważań na temat sytuacji, w której znalazłyśmy się w czasie pandemii. Nie jest ona udziałem wszystkich, być może nawet nie większości obywateli. Jest to sytuacja ograniczenia wychodzenia $\mathrm{z}$ domu, pracy zdalnej, ciągłego napięcia i strachu związanego z tym, co dzieje się za oknem. Jeżeli nie tym oknem domu czy mieszkania, bo przez nie być może nie zobaczymy nic zadziwiającego, to za oknem naszych monitorów dzieje się już znacznie więcej ${ }^{24}$. Gdy wielu z nas się zastanawia, jak świat się zmieni, warto wzrok skierować na siebie, do czego przyczynkiem być może była nasza akcja. Wreszcie - postawione w tekście pytania mogą służyć do interpretacji artystycznych i pozaartystycznych „dzienników z czasów zarazy”.

Chodzi o to, by w samotności przetrwać izolację, wyruszyć, tak jak uczestnicy akcji, w „teren”, który jest ich „ja” zawierającym się w przestrzeniach, ciałach, ludziach, zjawiskach atmosferycznych i przedmiotach. Po odnalezieniu tej samotności, a tym samym społeczeństwa w sobie, możemy nie powrócić, ale spotkać się ponownie w innych warunkach, $\mathrm{z}$ inną wiedzą, by zbudować nowe społeczeństwo. Jak to określiła Catherine Malabou, komentując kryzys wywołany pandemią Covid-19:

Podziwiam tych, którzy potrafią analizować obecny kryzys wywołany przez pandemię Covid-19 w odniesieniu do globalnej polityki, kapitalizmu, stanu wyjątkowego, kryzysu ekologicznego, strategicznych relacji między Chinami, Stanami Zjednoczonymi a Rosją itd. Osobiście na tę chwilę ja sama staram się być ,jednostkąa". Powtórzę jednak: nie wynika to z żadnego indywidualizmu, lecz, wręcz przeciwnie, z przekonania, że epoché, moment zawieszenia, wzięcia w nawias socjalizowania, bywa czasem jedynym dostępem do odmienności, sposobem na poczucie bycia bliżej wszystkich odizolowanych ludzi na Ziemi ${ }^{25}$.

Zamknięci w naszych domach niewątpliwie nadal borykamy się z trudnością bycia sami ze sobą. Od pierwszych dni izolacji zaczęto nas przyzwyczajać

24 E. Rewers, Post-polis. Wstęp do filozofii ponowoczesnego miasta, Kraków 2005, s. 68-69.

25 C. Malabou, Kwarantanna $w$ kwarantannie $i z$ dala od kwarantanny. Rousseau, Robinson Crusoe i „ja”, tłum. M. Krzykawski [w:] „Znak” 2020, nr 5 (maj), s. 56. 
do wydarzeń online, pracy zdalnej, codziennych briefingów itp. Pomocny w tej sytuacji może okazać się właśnie aparat (uwolniony od konieczności funkcjonowania jako narzędzie artystyczne), który pozwala na stworzenie dystansu wobec własnej codzienności i wyłonienie się pytań o to, jak i z czym żyjemy.

\section{Bibliografia}

Roland Barthes, Światło obrazu, tłum. J. Trznadel, Aletheia, Warszawa 2008.

John Berger, Zrozumieć fotografie, tłum. K. Olechnicki, [w:] Badania wizualne $w$ działaniu. Antologia tekstów, red. M. Frąckowiak, M. Krajewski, K. Olechnicki, Fundacja Nowej Kultury Bęc Zmiana, Kraków 2011.

Boris von Brauchitsch, Mała historia fotografii, tłum. J. Kożbiał, B. Tarnas, Wydawnictwo Cyklady, Warszawa 2004.

Jonathan Crary, Późny kapitalizm i koniec snu, tłum. D. Żukowski, Karakter, Kraków 2015.

Jakub Dziewit, Adam Pisarek, Ciemnia antropologiczna, [w:] Patrzenie i widzenie w kontekstach kulturoznawczych, red. J. Dziewit, M. Kołodziej, A. Pisarek, grupakulturalna.pl, Katowice 2016.

Jakub Dziewit, Adam Pisarek, Ocalać. Zofia Rydet a fotografia wernakularna, WUŁ, Łódź 2020.

Catherine Malabou, Kwarantanna $w$ kwarantannie $i z$ dala od kwarantanny. Rousseau, Robinson Crusoe i „ja”, tłum. M. Krzykawski, „Znak” 2020, nr 5 (maj).

Miłosz Markiewicz, Tożsamość zobrazowana, czyli o wartości zamykania oczu, [w:] Pomiędzy tożsamością a obrazem, red. M. Markiewicz, A. Stronciwilk, P. Ziegler, grupakulturalna.pl, Katowice 2016.

Nicholas Mirzoeff, Jak zobaczyć świat, tłum. Ł. Zaremba, Karakter, Kraków Warszawa 2016.

Anna Maria Potocka, Fotografia, Aletheia, Warszawa 2010.

Ewa Rewers, Post-polis. Wstęp do filozofii ponowoczesnego miasta, TAiWPN Universitas, Kraków 2005.

Roch Sulima, Antropologia codzienności, WUJ, Kraków 2000. 


\section{A Note from the Area of Everyday Life. Contribution to the reflection on isolation}

The authors of the essay present an analysis and interpretation of the photographic action Everyday Life Is Boring, which they performed in December 2019 as a part of the Ready for art. competition. Start! in BWA in Katowice. The essay is an attempt to look at the results of their animating activity. The starting point consists of ten photographs taken by the participants in the project, whose task was to present their everyday life using instax photography. Photographs Researchers draw the common points between photography and the outgoing researcher's activities, and propose to look at everyday life through the prism of time, space and attempts to mark their presence in the world through photography. The challenge that has been presented to the participants of the artistic activity becomes a metaphor for everyday life and the possibility of observing it in the light of home isolation imposed by the Covid-19 pandemic.

Keywords: isolation, pandemic, everyday life, photography, anthropology, animation of culture 